\title{
Groin Pain Resulting From Spondylodiscitis
}

Simon B. Zeichner, DO; Jillian Cepeda, DO; Radhika Shukla, DO; Michael Francavilla, MD; and Emin Hodzic, DO

From the Department of Internal Medicine (Drs Zeichner, Cepeda, and Hodzic) and the Department of Radiology (Dr Francavilla) at the Mount Sinai Medical Center in Miami Beach,

Florida, and the Broward Health Medical Center in Fort Lauderdale, Florida (Dr Shukla). Dr Shukla was a student at the Lake Erie

College of Osteopathic Medicine-Bradenton in Florida at the time of this case.

Financial Disclosures: None reported.

Address correspondence to

Simon B. Zeichner, DO, 4300 Alton Rd, Miami Beach, FL 33140-2948.

E-mail: simonzeichner @gmail.com Submitted January 23, 2013; final revision received February 20, 2013: accepted April 10, 2013.

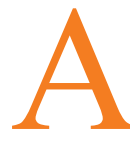
58-year-old man presented with a 1 -month history of dull right groin pain without back pain or fever. He denied a history of steroid use, diabetes mellitus, human immunodeficiency virus infection, intravenous drug use, or recent dental procedures. Physical examination revealed an indurated right groin without a cardiac murmur. Laboratory studies revealed the following: white blood cell count, 17000/ $\mu \mathrm{L}(83.1 \%$ segmented neutrophils); hemoglobin, $9.3 \mathrm{~g} / \mathrm{dL}$; platelet count, $757000 / \mu \mathrm{L}$; creatinine, $0.6 \mathrm{mg} / \mathrm{dL}$; and 1 of 2 blood cultures positive for Streptococcus intermedius. Results of computed tomography of the thigh revealed a $10.9 \times 5.7 \times 3.8 \mathrm{~cm}^{3}$ fluid collection, representing rupture of the fluid from the spine into the iliopsoas and retroperitoneum (image A). A magnetic resonance image of the lumbar spine demonstrated abscess extension from the T12-L1 neural foramen and vertebral end plate and disk inflammation consistent with spondylodiscitis (image B). The patient was given intravenous ceftriaxone ( $2 \mathrm{~g}$ every 12 hours) for 12 weeks. All cultures of the fluid collection and subsequent blood cultures were negative for S intermedius. (doi: 10.7556/jaoa.2013.054)

\section{Suggested Reading}

Zimmerli W. Vertebral osteomyelitis [clinical practice]. N Engl J Med. 2010;362(11):1022-1029.

(c) 2013 American Osteopathic Association
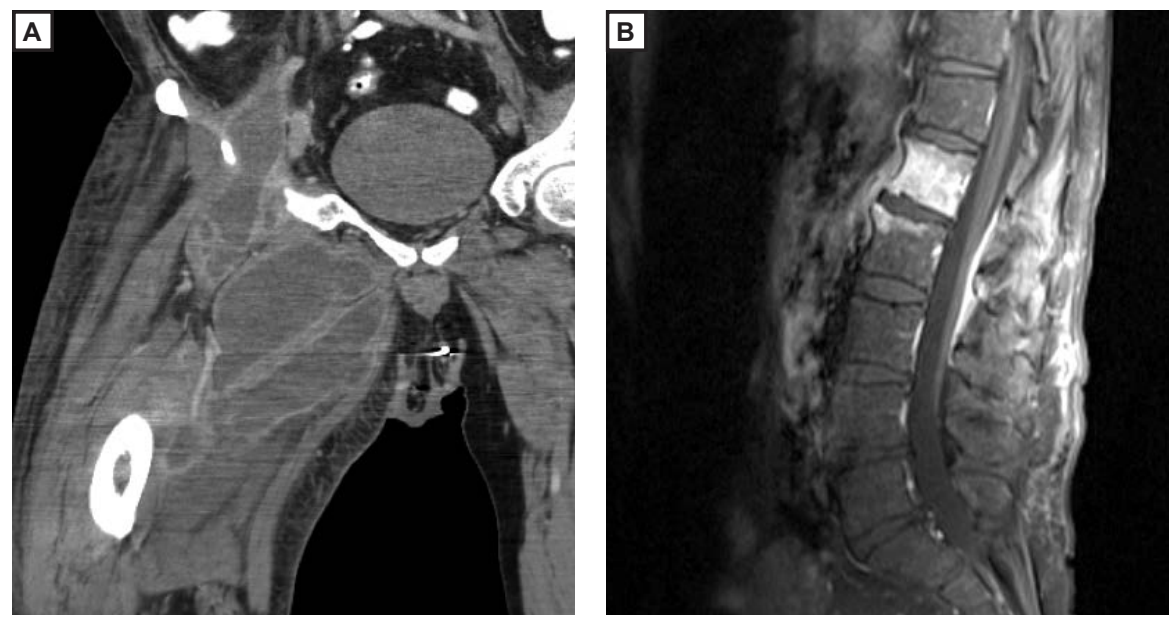